\title{
CiClo PADRÃO DE MEDIÇÃo DE CONSUMO AUTOMOTIVO EM DINAMÔMETRO DE BANCADA - UMA METODOLOGIA ALTERNATIVA PARA A FASE DE DESENVOLVIMENTO
}

\author{
Rodnei Rocha Júnior ${ }^{1,2}$, Thomaz Ernesto de Sousa Savio ${ }^{3}$, Gustavo Passarini ${ }^{1}$, Marcos \\ Fregoneze $^{1}$, Fernando Sarracini Júnior ${ }^{1}$ \\ ${ }^{1}$ Ford Motor Company \\ ${ }^{2}$ Faculdade de Engenharia de Sorocaba - FACENS \\ ${ }^{3}$ Instituto Tecnológico de Aeronáutica - ITA \\ E-mails: rodnei_rj15@hotmail.com, thomazernesto@ hotmail.com, gpassari@ford.com, \\ mfregone@ford.com, fsarraci@ford.com
}

\section{RESUMO}

O objetivo deste trabalho é propor um método mais eficiente e preciso para a medição de consumo de combustível durante o desenvolvimento de motores. Para isso foi criado um ciclo de dinamômetro de motor baseado em ciclo de emissões veiculares executado em dinamômetro de chassi. Os testes rodados em dinamômetro de chassi, além de necessitarem de elevado tempo de condicionamento entre testes, carregam consigo variações de processo como temperaturas e estilo de condução dos motoristas, o que gera problemas de repetibilidade e comprometem as medições de consumo de combustível. O método em dinamômetro de bancada, além de reduzir de forma significativa o tempo entre testes, ainda permite um controle aperfeiçoado das variáveis do processo, o que consequentemente traz maior repetibilidade aos resultados. Para este trabalho foi utilizado um motor Ford 1.0L de 3 cilindros, naturalmente aspirado e com injeção de combustível no pórtico. Os testes em dinamômetro de motor foram executados à quente com temperaturas estabilizadas. O resultado obtido foi um sistema com variação inferior a $1 \%$ nos resultados de consumo de combustível.

\section{INTRODUÇÃO}

Atualmente todos os processos buscam otimizar o tempo de cada operação e reduzir os custos, ou seja, mesmo os processos excelentes necessitam de melhoria contínua para se manterem em tal patamar. Este trabalho propõe uma forma de otimizar o teste de medição de consumo de combustível durante a fase de desenvolvimento de motor e calibrações, com maior rapidez nos testes e menor custo associado, replicando as rotinas convencionais do dinamômetro de chassis no dinamômetro de bancada.

A maneira convencional de se realizar um teste de medição de consumo de combustível é utilizando um dinamômetro de chassis. O dinamômetro de chassis consiste de massas inerciais, geralmente cilindros de inércia conhecida, que são submetidas à força motriz do veículo ensaiado. O veículo deve estar montado com suas rodas motrizes apoiadas diretamente sobre os cilindros de inércia. Neste caso são determinadas também as inércias do sistema de transmissão e das rodas (MARTINS, 2006). 
O teste realizado em laboratório de emissões segue a norma brasileira NBR-6601, onde o veículo simula uma viagem média, em área urbana. $\mathrm{O}$ ensaio completo em dinamômetro de chassis consiste em dois ciclos sendo um ciclo com partida à frio e outro com partida à quente, com intervalo de 10 minutos entre eles. O resultado é a média ponderada entre os ciclos de partida à frio e à quente, que representa assim, uma viagem padrão de aproximadamente 17,2 $\mathrm{Km}$. Além do veículo rodando, o teste requer outros cuidados especiais. O reservatório de combustível do veículo deve ser drenado totalmente e reabastecido com combustível para ensaio especificado. O veículo deve ser precondicionado, rodando em dinamômetro ou em pista por pelo menos 1372 segundos. Após o condicionamento, o veículo deve ficar parado em ambiente com temperatura controlada por no mínimo 12 horas. Na primeira fase do teste, temos a fase de partida a frio, onde o veículo é ligado na temperatura de $25^{\circ} \mathrm{C}$ e tem duração de 505 segundos, com um percurso de $5,7 \mathrm{Km}$. Na sequência, a segunda fase tem duração de 866 segundos e um percurso de $6,2 \mathrm{Km}$. A terceira fase se inicia dez minutos após o fim da segunda fase, realizando assim a partida com o motor quente. Em todas as fases, a condução do veículo é realizada por um piloto especialmente treinado para seguir as velocidades requeridas, que são mostradas em uma tela.

Para cumprir todas estas etapas, um teste convencional de medição de consumo de combustível requer cerca de 20 horas de trabalho. A repetibilidade dos testes é bastante influenciada pela habilidade do piloto em conduzir o veículo. A única forma de realizar mais testes no mesmo intervalo de tempo é construindo mais protótipos, o que encarece o desenvolvimento.

O dinamômetro de bancada ou de motores é uma máquina elétrica de corrente alternada que pode funcionar como motor ou como gerador. $\mathrm{O}$ campo desse dinamômetro é de excitação independente e, portanto, variando a alimentação de campo e rotor, consegue-se ampla variação de velocidade e de potências absorvidas. Este tipo de dinamômetro é o mais recomendado para trabalhos de pesquisas já que além de extremamente sensível, pode assumir configuração ativa, (BRUNETTI, 2012). Em um ambiente de dinamômetro de bancada é possível controlar as temperaturas do liquido de arrefecimento do motor, do óleo lubrificante e do ar de admissão além de utilizar um sistema digital para o controle de rotação e pedal do acelerador. Para a operação do dinamômetro de bancada é necessário a adequada instalação do motor, que contempla a instalação de sensores de temperatura e pressão, montagem dos acessórios essenciais ao motor (como filtro de ar e sistema de escapamento) e a programação do ciclo que será testado no sistema digital de controle. Todo o procedimento de instalação do motor no dinamômetro de bancada requer cerca de 24 horas, uma vez instalado este processo não precisa ser repetido.

O ciclo de desenvolvimento de um veículo leva cerca de 5 anos, das ideias iniciais até a chegada às concessionárias. $\mathrm{O}$ desenvolvimento do motor se inicia antes de existir um protótipo do veículo final, logo é razoável presumir que as fases de desenvolvimento de motor não buscam saber exatamente qual o consumo final do veículo (este é o objetivo da homologação final do veículo, o qual não se pretende substituir), mas entender se as estratégias de design e calibração serão benéficas ou maléficas ao consumo do motor. Construir um veículo experimental protótipo requer tempo e dinheiro, e nem sempre um protótipo tem as mesmas características que o veículo final, reduzir a quantidade de protótipos é a estratégia mais utilizada para reduzir o custo de um projeto. Por isso a motivação em propor uma metodologia que consiga avaliar as modificações de design e calibração do motor de forma rápida e com custo reduzido, sem requerer um veículo protótipo. 


\section{METODOLOGIA}

Um dos pontos da metodologia utilizada é a exclusão da fase fria do ensaio, do ciclo transportado para o dinamômetro de bancada. Isso se dá pela necessidade de tempo de condicionamento prolongado entre os testes na fase fria, o que atrapalharia na capacidade do sistema de controle do dinamômetro de garantir a repetibilidade das condições de contorno iniciais dos testes. Apenas os ciclos da fase quente do ensaio foram levados em consideração.

O primeiro passo para definir um ciclo de dinamômetro de bancada é analisar os resultados de um teste de dinamômetro de chassi. O objetivo deste trabalho é construir um ciclo de dinamômetro de bancada que seja mais repetitivo, rápido e mais barato do que um teste de consumo convencional. Porém não é objetivo deste trabalho replicar exatamente o procedimento já existente, portanto alguns ajustes serão considerados.

Foram considerados parâmetros de controle do motor: rotação e posição de pedal do acelerador. Para a criação do ciclo foi utilizado um teste em dinamômetro de chassi como referência, de onde foram aquisitados os parâmetros de controle do motor com taxa de aquisição de $10 \mathrm{~Hz}$. Para transformar os dados aquisitados em um ciclo de dinamômetro de bancada foi desenvolvido um programa na linguagem Matlab que transforma os dados discretos em segmentos de teste com padrão similar, possibilitando assim a programação deste ciclo no dinamômetro de bancada. A figura 1 mostra a correlação entre o teste de referência e o ciclo proposto. 

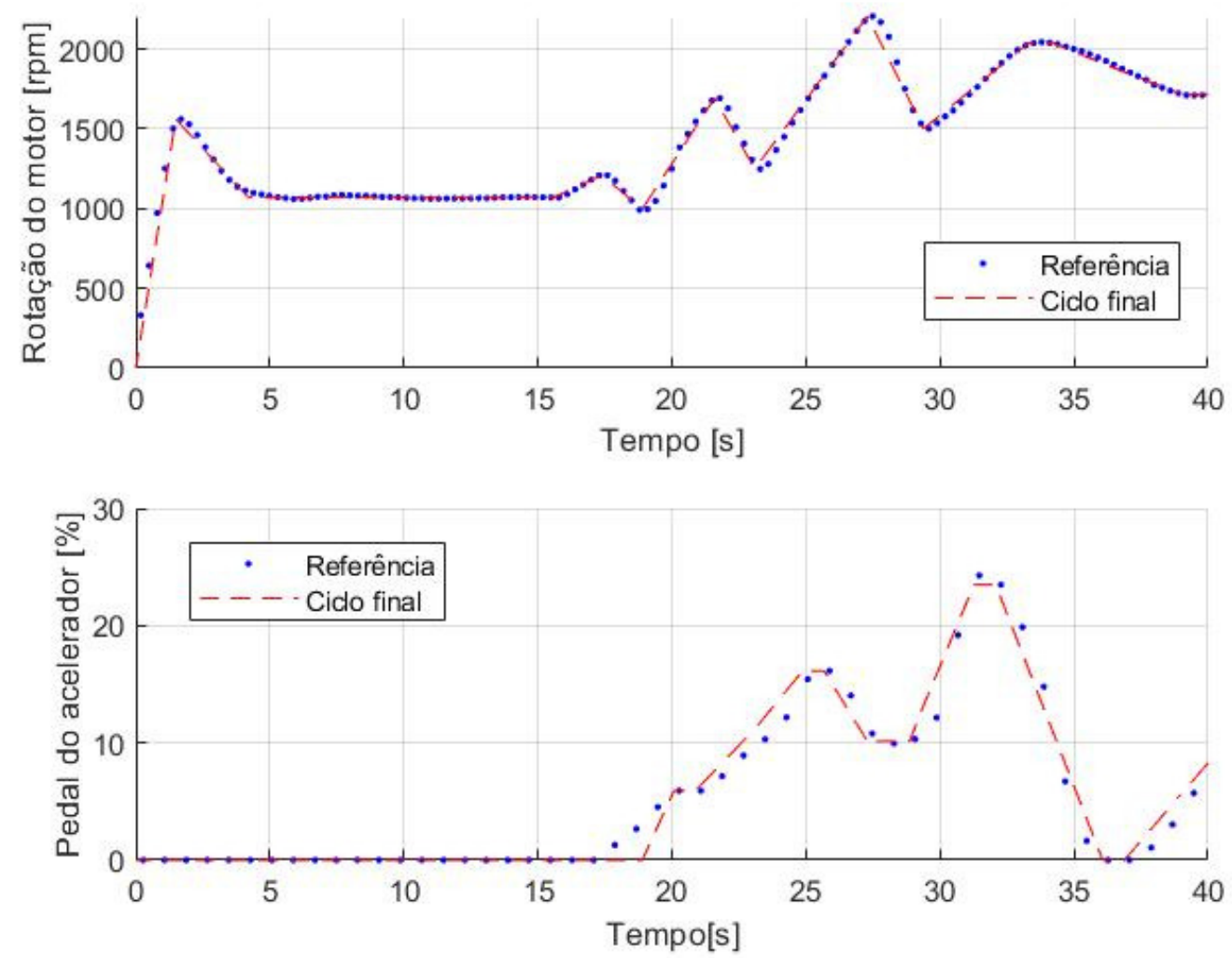

Figura 1: Ciclo de referência e ciclo final.

Na rotina desenvolvida, além dos dados do teste de referência, são inseridos os parâmetros de definição de segmento de teste. É considerado um segmento de teste um conjunto de pontos de rotação do motor ou de pedal (extraídos do teste de referência) sequenciais que apresentem o mesmo comportamento (crescente, decrescente ou estável). O conjunto de pontos que formam um segmento de teste são concatenados, formando assim uma linha média. Os parâmetros de definição são responsáveis por identificar o padrão de comportamento e assim formar os segmentos de teste. Neste trabalho utilizou-se como parâmetro de definição de rotação 40 $\mathrm{rpm} / \mathrm{segundo}$, para o pedal de aceleração utilizou-se 1.3 graus/segundo. Isto significa que se a média móvel de um conjunto de pontos de rotação apresentar uma derivada superior a 40 $\mathrm{rpm} /$ segundo, este conjunto de pontos será considerado um segmento de teste de rotação crescente. De modo análogo, se o conjunto de pontos apresentar derivada inferior a -40 rpm/segundo, será considerado um segmento decrescente, os pontos intermediários serão considerados segmentos estáveis. A figura 2 exemplifica o raciocínio descrito. 

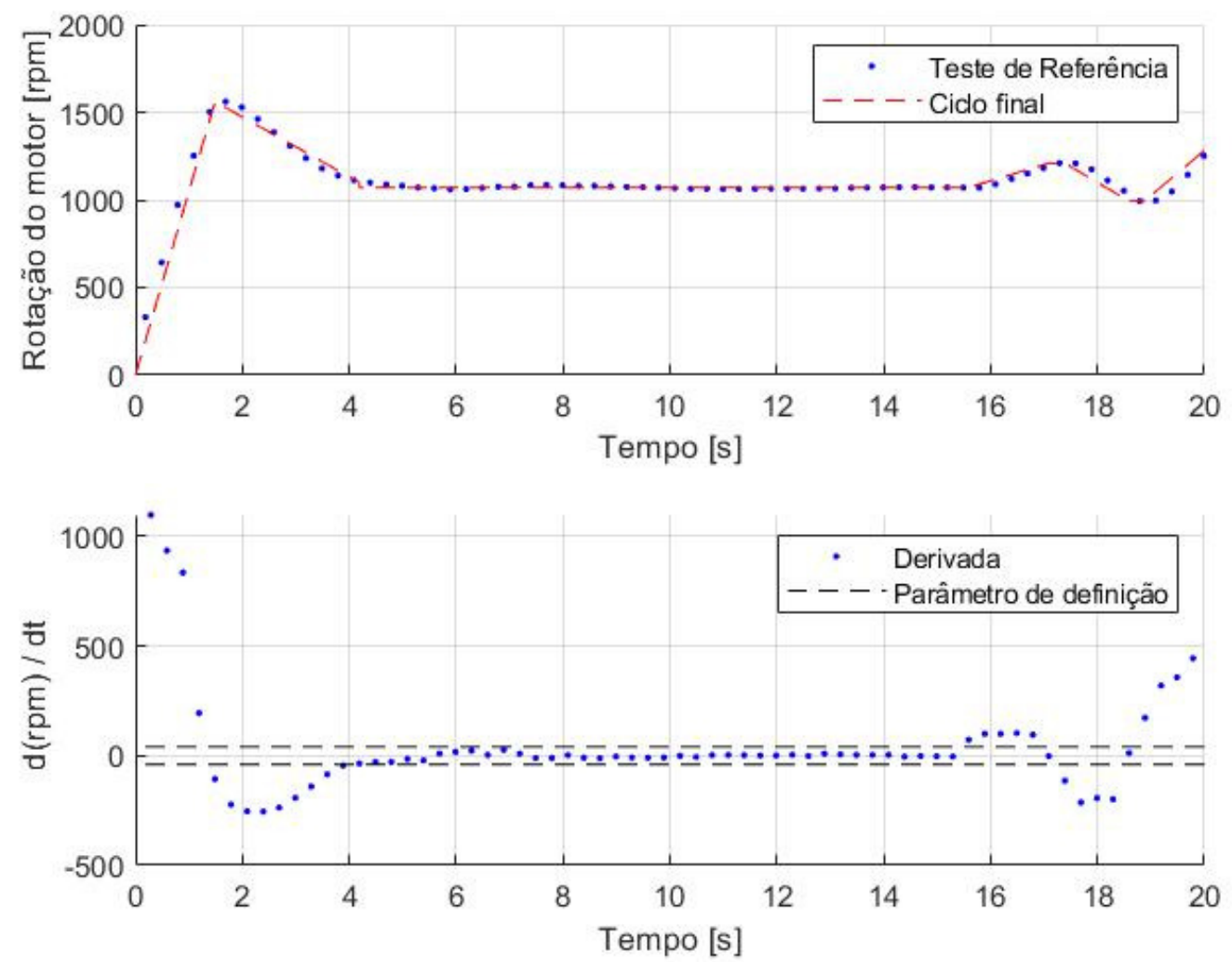

Figura 2: Construção de segmentos de teste para rotação.

Na figura 2 é possível observar que no primeiro segundo de teste, a rotação apresenta um padrão de comportamento crescente, com derivada bastante superior ao parâmetro de definição, logo estes pontos formam um segmento de teste. Após atingir o ápice de rotação desta primeira subida, a rotação inicia um comportamento de queda, formando um segundo segmento de teste. Após os 4 segundos de teste, a rotação apresenta um comportamento estável, formando assim outro segmento de teste. Quanto mais rigorosos forem os parâmetros de definição, mais segmentos de teste serão criados, portanto segmentos menores que são mais difíceis de controlar no dinamômetro de bancada, gerando ruídos no teste induzidos pelo sistema de controle do dinamômetro. Usando os valores apresentados nos parâmetros de definição, o teste de referência foi transformado em 663 segmentos de teste, criando assim o ciclo de dinamômetro de bancada.

Os resultados dos testes em dinamômetro de bancada são analisados usando medição direta para o consumo de combustível.

\section{RESULTADOS}

Para analisar a repetibilidade do dinamômetro de chassis, foram utilizados resultados de 201 diferentes testes, realizados no mesmo tipo de veículo, com a mesma configuração de powertrain, com a mesma calibração do módulo do motor, realizados no mesmo laboratório (portanto mesma altitude e temperatura), seguindo os mesmos procedimentos de condicionamento e tempo de espera entre testes. 
Para o dinamômetro de bancada, utilizando a metodologia proposta, foram realizados 30 testes com a mesma instalação de motor, utilizando a mesma calibração e com a mesma temperatura inicial de ciclo (líquido de arrefecimento à $90^{\circ}$ ).

A figura 3 mostra o resultado comparativo entre os dois métodos no que diz respeito à repetibilidade.
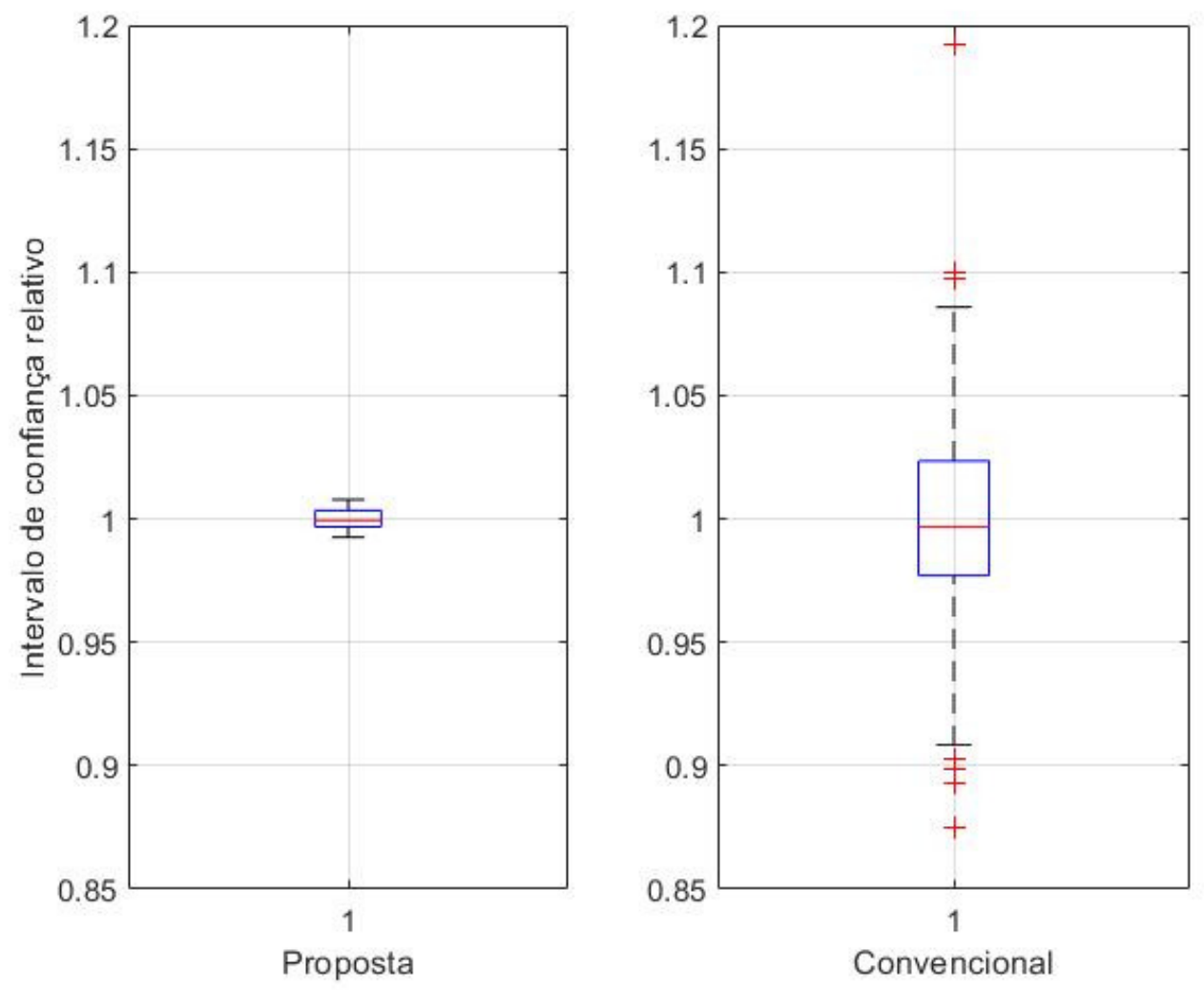

Figura 3: Resultados relativos do método proposto e do método convencional.

Por questões de confidencialidade, os resultados mostrados na figura 3 são relativos, ou seja, os resultados de consumo de combustível dos testes foram divididos pela média de cada conjunto, criando um conjunto adimensional. A análise de intervalo de confiança foi realizada utilizando-se este conjunto adimensional.

Fica evidente na figura 3 que o método proposto apresenta maior repetibilidade, atingindo assim o objetivo deste trabalho. Os 30 testes em dinamômetro de bancada foram realizados em 5 dias, utilizando apenas um motor, enquanto que os 201 testes no dinamômetro de chassis precisaram de muitos carros e muitos dias de trabalho. Sendo assim, fica comprovado que a metodologia proposta é mais rápida, barata e eficiente.

\section{CONCLUSÃO}


Pode-se dizer que a metodologia proposta atingiu os objetivos de repetibilidade, sendo possível com esta analisar inclusive a influência de modificações de design com impacto sutil na economia de combustível (como a modificação do óleo lubrificante). Acredita-se que o aumento de repetibilidade nos resultados é proveniente do controle digital do motor no dinamômetro de bancada, enquanto que no dinamômetro de chassis é feito por piloto humano. Apesar de existirem métodos de correção do consumo baseado no perfil do condutor, não é trivial corrigir numericamente os efeitos transientes, pois são característicos de cada motor.

Os testes da metodologia proposta foram realizados com menos recursos financeiros e de forma mais rápida, possibilitando assim o seu uso durante a fase de desenvolvimento (onde nem sempre existe um veículo protótipo disponível), auxiliando a tomada de decisões estratégicas de design por fornecer resultados confiáveis.

A metodologia proposta não visa substituir o teste de homologação ou os testes de conformidade de produção, tampouco mensurar o consumo de combustível final do veículo (pois este depende de outros fatores além do motor), por isso a ausência da partida à frio na metodologia proposta não tem impacto.

Como sugestão de continuação deste trabalho, os autores propõem a construção de um método que contemple na criação do ciclo de dinamômetro de bancada modificações além do motor, ou seja, inserir no ciclo contribuições provenientes de modificações na transmissão e aerodinâmica do veículo.

\section{REFERÊNCIAS}

[1] MARTINS, J. (2006). Motores de Combustão Interna.

[2] ABNT NBR 6601:2012.

[3] BRUNETTI, F. Motores de Combustão Interna Volume 1, 2012. 